\title{
Experiment, Theory, Representation: Robert Hooke's Material Models
}

\author{
Matthew Hunter
}

Robert Hooke's Micrographia of 1665 is an epochal work in the history of scientific representation. With microscopes and other optical devices, Hooke drew and then oversaw the engraving of Micrographia's plates, images that amount to little less than revelations from beneath the range of human vision (Fig. 1). In bristling detail, molds flower into putrid bloom, crystals protrude like warts from mineral skins and, for the first time in history, cells are brought to the eyes of a general viewership. So historical scholarship has shown us, Hooke was especially well equipped to make these wondrous images. A product of Oxford's lively scientific community of the 1650s and a protégé of the chemist Robert Boyle, he possessed intimate knowledge of the "new sciences" of the seventeenth century and a particular gift as an experimentalist. Indeed, from 1662 until nearly the end of his life, Hooke held the post of "Curator of Experiments" to England's premier scientific institution, the then newly-formed Royal Society of London. But, Hooke also had an additional advantage. Following some remarkable, juvenile feats of drawing, he had previously been apprenticed to Peter Lely, leading portrait painter of later seventeenth century England. Combining scientific training with tutelage in the art of portraiture - that most detail-attentive of pictorial genres (at least as practiced in seventeenth century England)_-Hooke would seem to have commanded the ideal skills for rendering the sights made perceptible through microscopes. Not surprisingly, Hooke's Micrographia has served as an important point of reference in recent studies of the interactions of art and science.

Yet, as the plates and pages of Micrographia attest, Hooke's investigations of nature also made use of representations that were neither pictures nor clearly picture-like. Directly below his elegant rendering of crystals in Micrographia's seventh plate, Hooke presents the viewer with a sequence of eleven incremental combinations of circular forms. So he explains, these diagrams denote not anything seen by a microscope, but patterns of crystalline vegetation he had generated by making groups of spherical "bullets" vibrate together. "If put on an inclining plain,

\footnotetext{
M. Hunter $(\bowtie)$

California Institute of Technology, Pasadena, CA, USA

e-mail: mchunter@caltech.edu
} 


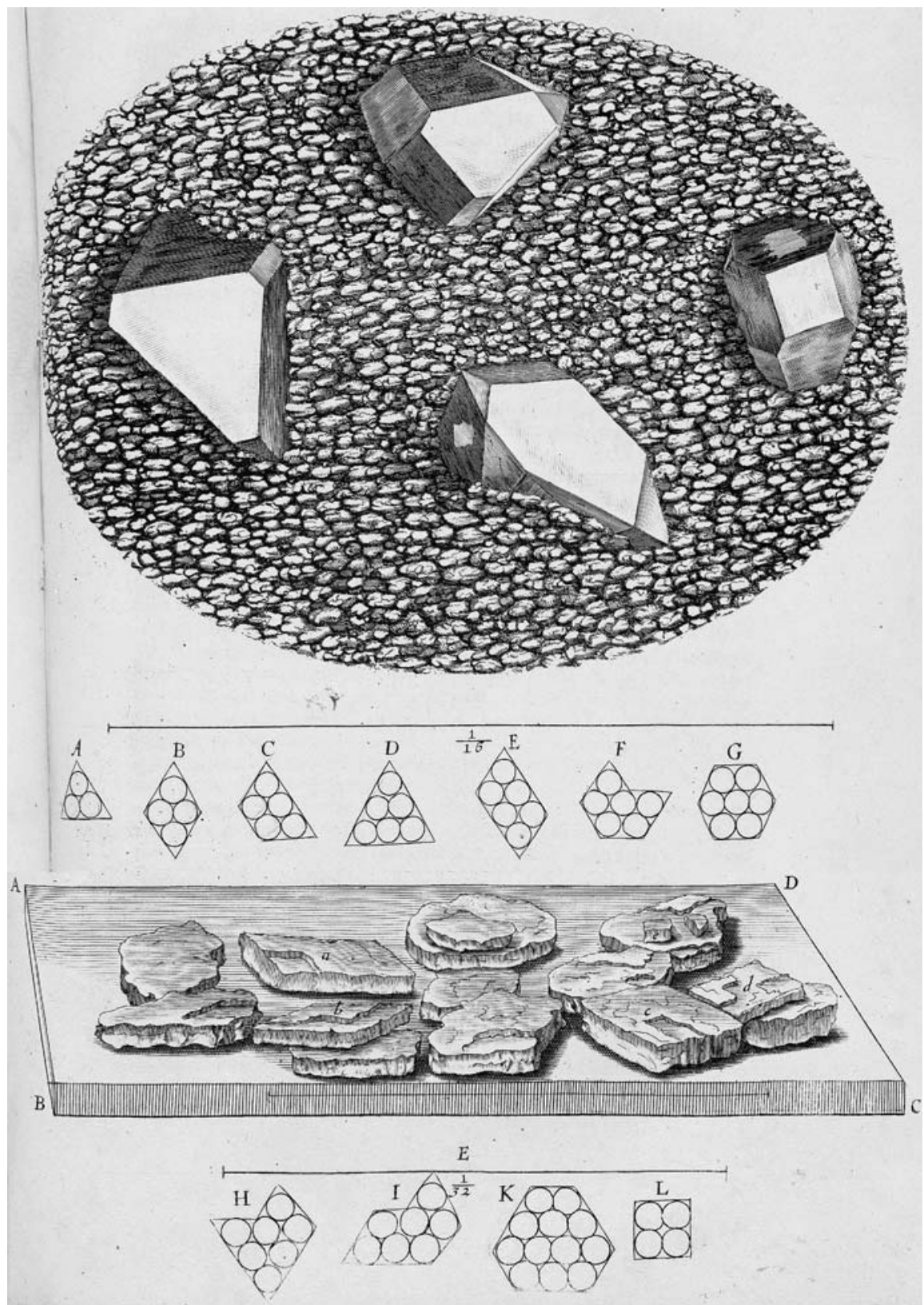

Fig. 1 Magnified mineral crystals and crystalline substructures from Robert Hooke, Micrographia (London: Jo. Martyn and Ja. Allestry, 1665), Scheme VII. This item is reproduced by permission of The Huntington Library, San Marino, California 


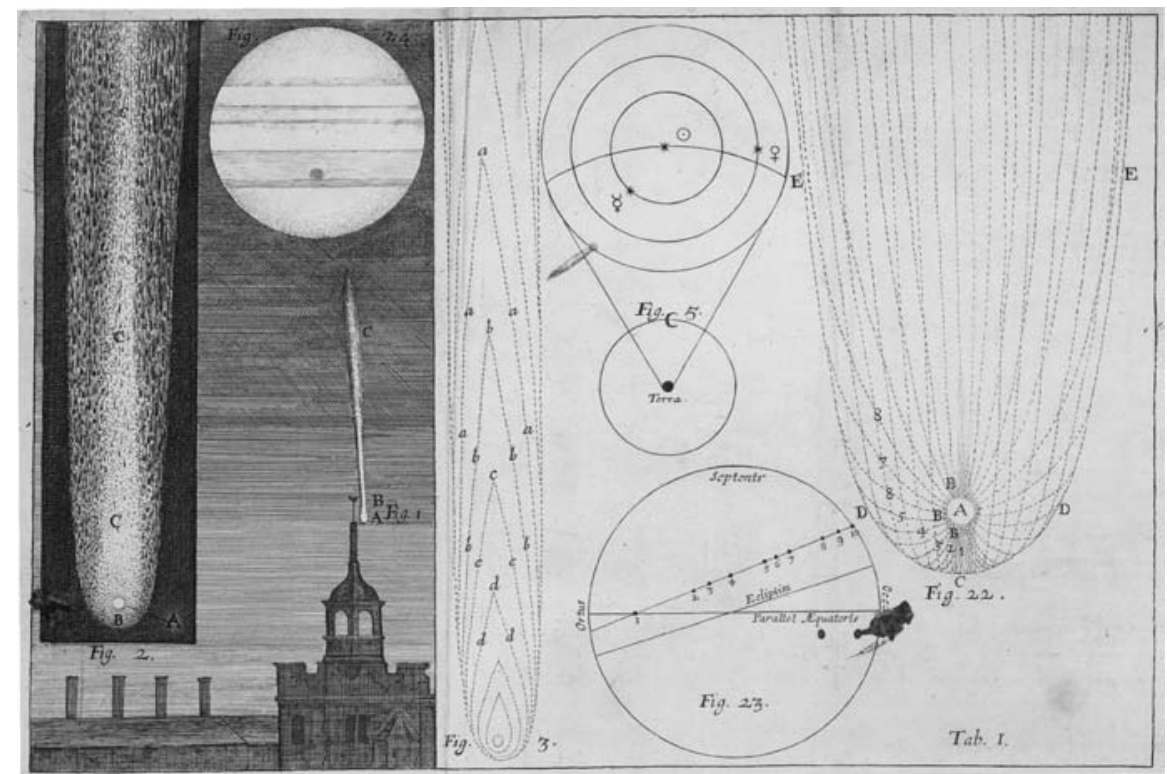

Fig. 2 Visible aspect and anatomy of comets from Robert Hooke, Lectures and Collections (London: Printed for J. Martyn, 1678), Table 1. This item is reproduced by permission of The Huntington Library, San Marino, California

so that they may run together", Hooke claimed, these bullets would "naturally run into a triangular order, composing all the variety of figures that can be imagin'd to be made out of aequilateral triangles" $(1665,85)$. A little over a decade later, Hooke published a treatise on a comet that had appeared over Northern Europe in the spring of 1677 (Fig. 2). Variously representing the comet's flight in accompanying prints, Hooke again detailed an action by which the meteoric object could be known. The reader is to suspend a wax ball covered with iron filings into a long beaker that has been filled with a solution of diluted sulfuric acid. Thus, Hooke proclaims, "you may plainly observe a perfect representation of the Head, Halo, and Beard [or tail] of the Comet" (1678a, 31).

What are these actions that Hooke proposes with agitated bullets and balls of wax in acid? How do these procedures, which are ubiquitous in Hooke's enterprise but rarely analyzed in historical studies, relate to his graphic representations? And what might art historians or philosophers of science learn from them?

By focusing upon these two particular cases from Robert Hooke's oeuvre, this essay aims to pursue a broader problem. That is, I suggest how researchers in the humanities and social sciences might learn from recent work in analytic philosophy of science to reconsider practices of representation shared between art and science. The time is particularly ripe for such rethinking. As philosophers in the analytic tradition have begun to look to the arts to understand the complexities of representations used in science, so art historians have increasingly sought to examine images 
made beyond the boundaries of the Western artistic tradition, especially those visual practices generated by the sciences. Nonetheless, for studies of the early modern period (ca. 1400-1800), the art of painting and modes of depiction proper to it have continued to guide thinking about representation. Spurred by the remarkably naturalistic feats of depiction that began to appear in early fifteenth century Florence and Bruges, researchers have sought to identify profound shifts in the orders of scientific knowledge embodied therein. As one recent scholar has asked: "Why did naturalism in painting arise with the new science? What was the relationship between artistic and scientific representations of nature in early modern Europe?" (Smith 2004, viii).

Address to such questions has certainly advanced our understanding of the vital cross-pollinations between pictorial art and empirical science in early modern Europe. Significant work in art history, for example, has demonstrated how-from Leon Battista Alberti's "rationalization of sight" to Vesalius' anatomies and on to Galileo's studies of the moon-representational techniques generated by early modern painters materially advanced techniques of scientific illustration and investigation (Ivins 1938, Pächt 1950, Panofsky 1962, Edgerton 1984, Bredekamp 2000). A reciprocal strain of historical study has explored how optical sciences and instruments informed the naturalistic turns of painting in Renaissance and Baroque Europe (Lindberg 1976, Steadman 2002, Kemp 1990, Hockney 2001). And more recent, interdisciplinary literature aligned with "science studies" has emphasized how the mimetic naturalism exemplified in early modern painting might be seen as a general model for the aspirations of the emergent natural sciences. "The picture in general, and painting in particular", so one such study has claimed, “... emerges as a dominant paradigm for the whole system of modes of representation constitutive of early modern philosophy, religion and science as well as literary or aesthetic culture" (Braider 2004, 46).

Robert Hooke has figured significantly in the formulation of these positions. In a hugely influential work from 1983, art historian Svetlana Alpers (1983) cast Hooke as a leading exemplar of the "descriptive impulse" - the penchant for the detailattentive, naturalistic "picturing" of appearances - that she identified in the still-life and genre paintings of Dutch art, and ascribed generally to the science and culture of seventeenth century Northern Europe. Posed by Alpers as a heuristic corrective for viewing the Northern European pictorial tradition outside of the hegemonic standards of Italian art, descriptive picturing has itself become a norm. Especially in studies of the early modern period, talk of copying or picturing nature has become paradigmatic for discussions of representation in scientific contexts (Shapin and Schaffer 1985, Ogilvie 2006). ${ }^{1}$ In turn, this apparent sympathy of aims between artistic and scientific representation has given a new encouragement to studies of art in Hooke's native Britain. Increasingly, researchers have looked to the Royal Society, and to Hooke specifically, for sources of an empirical bent that can be traced into the rising tradition of eighteenth century British painters such as William Hogarth and John Constable (Bermingham 2000, Gibson-Wood 2000). If artistic

\footnotetext{
${ }^{1}$ Interesting variations upon this direction are Freedberg (2002) and Daston and Galison (2007).
} 
training informed the gaze of scientists like Hooke, this story suggests, so their empirical ethos should be seen as underpinning the pictorial achievements of the Enlightenment.

The objective of this essay is neither to take issue with these readings nor to re-stage old debates over the adequacy of Alpers' notion of "description" for understanding early modern painting (de Jongh 1984, Marin 1986). Indeed, if my point of departure is to ask whether this approach offers compelling terms for understanding the material models of Robert Hooke, my argument aims to complement the broader rethinking of art in later Baroque Britain. I do so by showing how recent philosophy of science enables us to apprehend the representational sophistication and sheer imaginative virtuosity of Hooke, Christopher Wren and their colleagues in the early Royal Society with new clarity and vigor.

Certainly, there is enough in Hooke's work to encourage the reading already available to humanities-based scholarship. Beyond his apprenticeship to the Netherlandish painter Lely, Hooke was a keen advocate of accurate representation whose scientific writings deploy various concepts from the "mimeticist tradition" (Halliwell 2002). Nonetheless, recent historical research has identified two important reasons for reconsidering this dominance of the pictorial. The first reason is a matter of focus. As historians of the built environment have shown, Royal Society Fellows like Hooke and Wren simply produced a huge body of visual work that was not pictorial. Central agents in the rebuilding of London after the fire of 1666, their collective endeavors like engineering the dome of St. Paul's Cathedral or designing telescopic observatories and mental hospitals are fascinating intersections of artistic and scientific endeavor; but they have little obvious relationship with the terms of pictorial representation (Cooper 2003, Stevenson 2005, Jardine 2003a, b). The second reason for reconsidering the interpretive appeal to painting is a matter of relative value. Historians of art have long lamented that painting was significantly underdeveloped in seventeenth century Britain, especially in comparison with Continental models (Waterhouse 1953, Pears 1988). While numerous, competing painting schools flooded the sophisticated art markets of the seventeenth century Netherlands and painters received royal patronage of their academy in Louis XIV's France, indigenous pictorial traditions in Britain prior to the eighteenth century are, by contrast, notoriously fragmentary. ${ }^{2}$ Hardly an unalloyed good let alone a paradigm of knowledge, the art of painting was, moreover, a practice from which many English scientists sought to distance themselves and the representations they did employ. If his scientific colleague William Cole dismissed painting and sculpture as "things uselesse" pursued only for the "lusts of pride and ostentatious vanity" (ca. 1692, f 159), Hooke himself treated pictures with caution. "The Pictures of Things which only served for Ornament or Pleasure", he warned, are "... rather noxious than useful, and serves to divert and disturbs the Mind" (Hooke 1705, 64). And while advocated by some of the Royal Society's gentlemen-amateurs,

\footnotetext{
${ }^{2}$ For a revision of this argument, see Gibson-Wood (2002).

${ }^{3}$ On these points more broadly, see my (2010).
} 
evidence suggests that the kind of naturalistic pictures most valued by recent interpreters is precisely that which Hooke and Wren performed early in their careers and subsequently delegated to their assistants (Hunter 2007).

If a focus upon painting thus feels like an increasingly arbitrary imposition upon the visual activities and values of Hooke and his circles, the conceptual situation becomes even worse when their expressly scientific representations are examined in detail. Ostensibly, this would be the business of the history of science. But, despite the fact that they were performed and studied at the very center of scientific communities like the Royal Society, historians of science have had very little to say about the representational structure of events like Hooke's bullet manipulations and his effervescent wax comet. Instead, studies have tended to focus upon various sociopolitical objectives accomplished through such performances or via images related to them (Shapin and Schaffer 1985, Fyfe and Law 1988, Golinski 1989, Lynch and Woolgar 1990). Without disputing the interest of such work, the complementary proposal of this essay is simple. Before we reduce these largely-uncharted seas of visualization to the terms of mimetic naturalism - and before we art historians construct elaborate pre-histories of Enlightenment art upon them-it behooves students of science and art alike to first analyze those representational operations in which Hooke's community invested so much epistemological and financial capital. To do so, researchers in the humanities and social sciences can learn much from emerging work in analytic philosophy of science.

To this project, Hooke's aforementioned performances present at least three significant, interpretive obstacles; I will call these concerns methodological, categorical and quasi-existential. To an art historian, the major methodological problem is obvious: when considering procedures such these, frequently no object survives around which to organize analysis. At the very least, we would want to know if the spherical bullets or the glass beaker Hooke claimed to use for his actions possessed (or, as we will see, could have possessed) some unusual properties that made them uniquely capable of representing his targets of investigation. Surely it is true that, as the remit of art history has expanded in recent decades, the graphic resources, theoretical writings, and other kinds documentation upon which I will draw in this analysis have eroded the privileged evidentiary position once commanded by the art-object. But, given the discipline's residual methodological orientation toward objects (Koerner 1999), the approach I employ here has been to attempt to supply, as it were, replacement objects, using a modest version of the strategies of replication developed in the history of science. ${ }^{4}$ And here, the methodological conservativeness of art history may actually become a virtue as it forces us to focus upon exactly how Hooke's models were supposed to have worked and what roles physical objects could have (or could never have) played in them.

More substantial is the second, categorical concern. To some readers, the interpretation ventured here might be read as committing a category error by treating as representations what should really be understood as experiments, the central means

\footnotetext{
${ }^{4}$ For a recent application of this approach with a useful bibliography, see Heering (2008).
} 
of intervening into reality advanced by Hooke and his colleagues. Because representation and experiment are not only distinguished from but often opposed to one another in philosophical accounts, address to this categorical concern must be central to this and other studies of experimentalist representation. It is with this worry that I will begin. The third concern, though, is almost an existential one. That is, why should art historians care about the strange performances of brilliant but eccentric characters like Robert Hooke? What does this tell us about art? I will engage these quasi-existential charges directly only in the conclusion; but my analysis follows from the conviction that how we answer these questions powerfully reveals what we want explorations of the art/science conversation to do. Building from work by scholars like James Elkins and Peter Galison, my contention is that humanitiesbased studies of visual materials only become more interesting and intellectually rigorous as we increase our engagement with science. (Elkins 1999, 2007, 2008, see "Visual Practices Across the University" this volume, and Galison 1997) Therefore, if we want to understand how representation in art and science might speak to one another-indeed, if there are more than passing coincidences between naturalism in art and empiricism in science-then we need to scrutinize the representational procedures that were central to emerging science with as close attention as has been paid to practices of representation in art.

This, then, is not just a call for interdisciplinary dialogue for its own sake. For, if these methodological, categorical and quasi-existential worries can be allayed, what becomes available to interpretation is an excitingly open, but absolutely central, field of inquiry wherein representation may be approached anew. Released from the powerful gravitational pull of painting, art historians might begin to reckon more successfully with the visual achievement of Hooke, Wren and their colleagues who remain highly problematic to available accounts. Beyond learning from the flexibility, stylization and deep inaccuracies of scientific representations as they appear in recent philosophy of science, moreover, I show how historians can productively draw from this literature to reconsider what kinds of cognitive work representations were being asked to perform in early scientific contexts; why diverse styles of representation could have been useful; and what modes of knowledge they might be said to embody. Reciprocally, historically-based contributions such as this one may bring to philosophical consideration how play between graphic imagery, performance with material models, and theory deserves to be integrated into more generalized accounts of representation as practiced in the arts, sciences, and beyond.

\section{Gross Similitudes}

I want to begin by returning to the categorical concern sketched above. That is, are the procedures Robert Hooke described with bullets or his operations with wax balls in acid really representations at all? The question deserves to be posed because an important tradition within philosophy of science has seen Hooke as exemplary of a significant shift within the sciences, one defined by the differentiation of 
experiments from representation. Thomas Kuhn has counted Hooke among those who inaugurated this qualitative shift in the enterprise of experimentation in the seventeenth century. From antiquity through the Renaissance, Kuhn argues, everyday observation and the exercise of reason had been sufficient grounds for competence in major fields of physical science. Experiment in this pre-modern context was properly thought experiment, which aimed at demonstration of known principles or exposition of their particulars. By contrast, Kuhn claims, when "men like Gilbert, Boyle, and Hooke, performed experiments, they seldom aimed to demonstrate what was already known or to determine a detail required for the extension of existing theory. Rather they wished to see how nature would behave under previously unobserved, often previously nonexistent, circumstances" $(1977,43)$. In this new, "Baconian" definition of the seventeenth century, experiment was radically productive of data and, by that measure, not re-presentational at all. Ian Hacking has influentially endorsed a similar view of Hooke the experimenter. In Hacking's memorable words, Hooke was "a crusty old character who picked fights with people - partly because of his own lower status as an experimenter" (1983, 151). Because of the field's bias towards theories and representations, Hacking claims, philosophers of science give scant attention to experimentalists like Hooke who were committed to manipulating reality. By these views, Hooke is not only to be strongly identified with experiment, but he figures among those crucial, historical agents who brought into being practices of experiment that could be meaningfully differentiated from representation for the first time.

If his work abounds with examples, Hooke's theoretical writings shed only limited light on these boundaries of experiment. In a famous paper from the early 1660s, for example, Hooke defines the "Reason of making Experiments" as the very general aim of "Discovery of the Method of nature in its Progress and Operations" (Hooke 1726, 26). What available literature there is on Hooke's experimentalism also encourages softening philosophers' categorical distinction between representation and experiment. Social historians of science have emphasized how the experiments performed at the Royal Society's meetings in the later seventeenth century were rarely the bald confrontations with nature as envisioned by Kuhn. Experiments would be tried extensively in private laboratories before their demonstration to the scientific fellowship. So Steven Shapin has contended, "the weekly meetings of the Royal Society required not trials [of experiments] but shows and discourses" $(1999,497)$. In this reading, a public experiment was always a kind of representation insofar as it was a demonstrative replication of results previously obtained elsewhere. But, in turning specifically to analysis of Hooke's trials, I want to consider if and how a project like the bullet manipulation can be seen to participate in experiment's celebrated intervention into nature at all.

In Micrographia, Hooke introduces the bullet manipulation in the context of his microscopic observations of flint, casserite, alum and other mineral crystals. [See Fig. 1] Why, Hooke asks, do minerals like these betray remarkable formal consistencies? By way of explanation, Hooke appeals to a significant component of his physical thought, the theory of congruity. As Mary Hesse (1966a) has noted, Hooke understood diverse physical phenomena disclosed by his experiments to be 
products of particulate matter in vibrating motion. In turn, his theory of congruity stipulated that bodies of the same (or proportional) mass or vibrating frequency would attract one another; "incongruous" bodies, which have different masses and non-proportional frequencies, would repulse. In his later writings, Hooke could formulate this theory in economical terms as "nothing else but an agreement or disagreement of Bodys as to their Magnitudes and motions" (1678b, 7). But, in early works like Micrographia, congruity and incongruity are often suggested through a catalogue of vibrating phenomena. The cohesion of congruous bodies, for example, is explained in the following terms:

I suppose the pulse of heat to agitate the small parcels of matter, and those that are of a like bigness, and figure, and matter, will hold, or dance together, and those which are of a differing kind will be thrust or shov'd out from between them; for particles that are all similar, will, like so many equal musical strings equally stretcht, vibrate together in a kind of Harmony or unison $(1665,15)$.

Although they generally agree on the importance of Hooke's theory of congruity to his broader mechanical philosophy, historians of science have been divided on its implications. John Henry (1989) and Penelope Gouk (1999) have read Hooke's materialism as a continuation of Renaissance natural magic, while Mark Ehrlich (1992) and Michael Hunter (2003) see his matter theory as characteristic of the rationalizing tendencies in seventeenth century science which would form the basis of classical mechanics. Most interestingly, Ofer Gal (2002) has argued that because Hooke's theory of congruity was a key component in his thinking on attraction at a distance, it might be seen as having material consequence for the theory of universal gravitation elaborated by his sometime-interlocutor and later great enemy, Isaac Newton.

However its influences and intricacies may be parsed out, the key point here is that Hooke's theory of congruity closely shadows his bullet operation. Because of the force of congruity, Hooke explains, homogenous matter in its most fluid, agitated form would be "driven ... and forc't into as little a space as it can possibly be confined in" $(1665,17)$. When highly agitated, this congruous matter would form into spheroids, which he calls "globules". Hooke's contention is that crystal patterns in minerals can be explained by appeal to "three or four several positions or postures of Globular particles, and those the most plain, obvious, and necessary conjunctions of such figur'd particles that are possible" $(1665,85)$. Support for this claim is then offered by the bullet trial itself. So Hooke explains in full:

\footnotetext{
I have ad oculum demonstrated with a company of bullets, and some few other very simple bodies ... that there was not any regular Figure, which I have hitherto met withal, of any of those bodies that I have above named, that I could not with the composition of bullets or globules, and one or two other bodies, imitate, even almost by shaking them together. And thus for instance we may find that the Globular bullets will of themselves, if put on an inclining plain, so that they may run together, naturally run into a triangular order, composing all the variety of figures that can be imagin'd to be made out of aequilateral triangles $(1665,85)$.
}

At the most basic level, then, bullets vibrated on an inclined plane are claimed to yield the kinds of formal configurations observable in mineral crystals. 
So, is this an experiment? An informative way into this question is simply to press upon how Hooke's procedure was supposed to have worked. Even the most fundamental aspects of this action are problematic. Hooke contends that bullets (a term, according to the OED, derived from the diminutive of the French boule, thus a small round ball) in his manipulation would move into the geometrical forms he diagrams "even almost by shaking them together" $(1665,85)$. Yet, such behavior runs counter to the major works of seventeenth century physics, which Hooke knew well. In Two New Sciences (1974, 87-88), Galileo had outlined how balls moving on an inclined plane (the trial situation Hooke stipulates) would attain identical velocities if the resistance of air and friction are eliminated. In the terms formulated by Newton some twenty years after Micrographia, the bullets would be expected remain in rectilinear motion until acted upon by other forces, reacting equally and oppositely to their encounters with other bullets (Newton 1989, 14-24). Hooke's bullets behave otherwise. They do not scatter or project off the edges of the trial surface, but gather into regular groups. [See Fig. 1]

For his part, Hooke is extremely vague about the exact nature of the trial, explaining nothing of the friction, agitation and angle of the plane nor the masses, diameters, or possible velocities of his bullets. Perhaps it is possible that the patterns of attraction between bullets that Hooke describes could have been achieved had his spheroids possessed some degree of magnetism, a property on which Hooke experimented and clearly saw as related to his notion of congruity $(1665,31)$. Yet, no such property is ever stipulated for the bullets in the trial and Hooke even suggests that the specified results can be achieved with non-magnetic objects. Although the frailties of Hooke's experimental contrivances have become well known to recent historians (Shapin and Schaffer 1985), the only success I have had at replicating the stipulated behavior with non-magnetized "bullets" has come from introducing the spheroids into a bowl and not on the inclined plane Hooke describes (Fig. 3).

Baffling as it is, the physical difficulties, if not impossibility, of Hooke's bullet operation helps to clarify its objectives. Rather than seeing it exclusively as an experimental intervention that produces new data from a natural target, the trial might be better conceived as a mechanism through which a theoretical precept (namely, the theory of congruity) can be visualized to understand a phenomenon (here, the formal regularity of mineral-crystal formation). In this capacity, Hooke's trial has a clear representational aspect. Parsed in crude terms, the bullets represent theoretical entities called globules, while the agitation of the inclined plane simulates the vibrating motion of congruity; I want to return momentarily to the procedure's semantic dimensions and particularly to what might be called its "enigma of representation". According to the representation's logic, incremental addition of bullets is claimed to reveal the possible field of formal permutations available to crystals. By using " 25 , or 27 , or 36 , or 42 , \&c." bullets, Hooke insists, the scientist can "find out all the variety of regular shapes, into which the smooth surfaces of [a mineral like] Alum are form'd" $(1665,86)$. Thus, if we disregard its practical mechanics for a moment, the bullet manipulation might be read as both a visualization of the rudimentary component particles and forces yielding crystalline structures and a means for generating rules of combination with which to predict the target's possible patterns at higher 
452

453

454

455

456
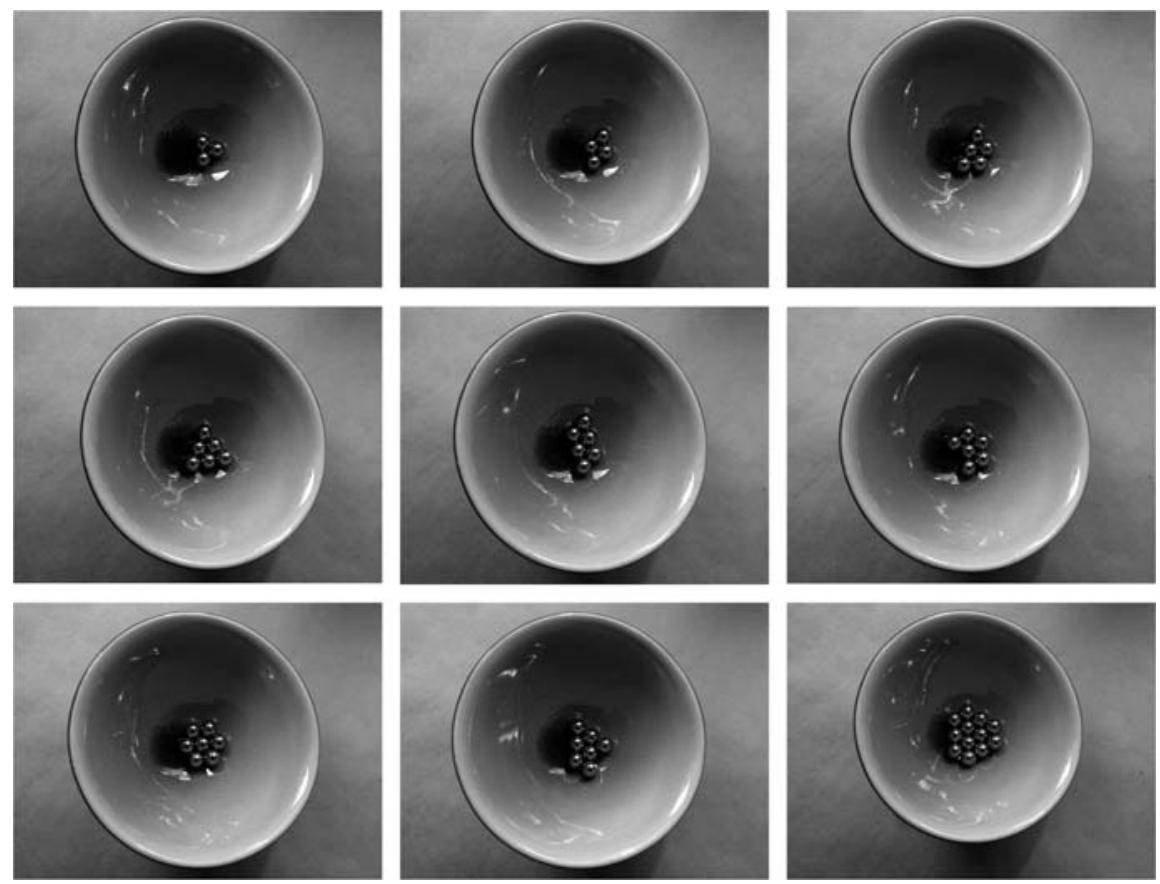

Fig. 3 Author's reconstruction of Hooke's bullet manipulation. This replication was produced by incrementally introducing stainless steel ball-bearings (diameter: $1 \mathrm{~cm}$ ) into the curved surface of a shallow bowl (roughly parabolic curvature, diameter: $14 \mathrm{~cm}$, depth: $6 \mathrm{~cm}$ )

levels of formal complexity. The bullet trial is a representational process that produces data from an artificial situation as a means to understand a natural target. By this reading, Hooke's bullets can be understood as a model of crystallization (Frigg and Hartmann 2006).

Arguably, art historians are better equipped to study the data produced by this representation than to interpret Hooke's crystallization model itself. For, in this case, the data are graphic images. Hooke has transcribed the model's informational yield in Micrographia's figures A-L where the resulting bullet-patterns are rendered as sequences of spare, circular forms circumscribed within geometrical solids. (Fig. 1) No doubt an interesting art-historical account might be written by narrating how Hooke's denotation of the spherical bullets as abstract geometrical entities fits in histories of crystallographic representation, the larger development of diagrammatic notation, or the anti-naturalistic tendencies of later seventeenth century scientific illustration. ${ }^{5}$ Yet, what is crucial to underscore are the two stages of representation

${ }^{5}$ On these topics, see respectively Elkins (1999, 13-30); Wilson (2002); and Freedberg (2002). 
disclosed by attention to these diagrammatic figures in Micrographia. This doubled reference might be schematized in the following way:

$$
\text { Figures }---(\text { depict })-->\text { Bullets }----(\text { represent })-->\text { "Globules" }
$$

As is signaled by the parentheses, no particular accounts of reference are yet subscribed to here. But, the fundamental point is this: by whatever means we might explain how Hooke's inked markings in Micrographia answer to the bullets he claimed to have manipulated, the vexing relationship between those bullets and "globules" still demands explanation as well. It is upon this second, neglected half of the schematic figure that I will focus in the analysis that follows.

Let us return, then, to the "how" of Hooke's crystallization model. In outlining directions for expanded thinking on scientific representation, philosopher of science Roman Frigg has described what he calls "the problem of how models represent their targets as 'the enigma of representation'" (2006, 50). Frigg's terms are particularly appropriate to Hooke's perplexing crystallization model. Indeed, it is both perplexing and mysterious; there is no documentation of the model's performance at the Royal Society and all we know about it comes from the pages of Micrographia. There, Hooke had claimed that crystals are naturally formed by the vibrating motion of matter as it gathers into particles called globules. Governed by congruity and incongruity, globular matter then consolidates into regular crystal patterns. If, as has been suggested, Hooke's model makes bullets stand for globules and a vibrating inclined plane represent the conditions of congruity, by virtue of what is this a representation?

Following the dominant interpretive approach, we might account for these enigmatic properties by appealing to criteria of depiction as borrowed from the model's representation in Micrographia's plate. Depicting and representing, as indicated in the scheme above, would thus be the same. And following Hooke's earlier appeal to the bullets' "imitative" capacity, we might read the whole enterprise through the central vein of mimesis in which early modern European learned cultures understood human arts. In this tradition inherited from Classical antiquity, such artifice followed from a universal human compulsion to mimic. Where Aristotle had identified the sources of these techne mimetike in the pleasures of making and decoding imitations, artisans across pre-modern Europe put these pleasures to work as copying of schemata made by master craftsmen became the literal core of apprenticeship and the prolegomenon to study of the privileged subject of art, the human body. (Aristotle 1987, Gombrich 1960, Muller et al. 1984) But, among intellectuals eager to secure the elevated status of painting and sculpture, the mimesis proper to what would come to be called the "fine arts" was understood to be based in imitation of ideas generated in the mind of the artist. (Panofsky 1968, Belting 1996) As a work of genius, this artistic imitation was to originate in but transcend observed, imperfect nature by reconciling it with idealized conceptions. "Noble painters and sculptors", so claimed Hooke's contemporary Giovan Pietro Bellori, “... form in their minds an example of higher beauty, and by contemplating that, they emend nature without fault of color or of line" $(2005,57)$. Rich and various as its permutations are, imitation in this ennobling tradition of early modern artistic academies was centrally concerned with idealization (Lee 1940). 
Academic idealization was, of course, not the only option to which a figure like Hooke could turn; part of what motivated claims like Bellori's was the perceived influence of apparently non-idealizing modes of imitative depiction. Notorious in artistic circles were painters like Michelangelo Merisi da Caravaggio whose putative commitment to the imitation of nature in extremis threatened the supposed dignity of art (Marin 1995). As recent scholarship has emphasized, these naturalistic currents can be seen in instructive dialogue with the cultures of science emerging across sixteenth and seventeenth century Europe (Crombie 1994, Smith 2004). While numerous examples might be mustered from Hooke's activities to corroborate his interest in such naturalistic imitations-from picture-making with the camera obscura to casting carp from life-his own writings are most succinct. Nothing, Hooke would observe in a planned introduction to a universal atlas, is "more conducive to the assistance of the memory understanding and memory then a plaine simple cleer and uncompounded Representation of the Object to the Sense" (ca. 1680, f 2). It is this non-idealizing "descriptive" mode of depiction that has served to characterize Hooke's representational activity and the central visual concerns of the Royal Society more broadly.

The problem with this account is that it is simply difficult to see what light it sheds on representations like Hooke's bullets. Descriptive picturing and naturalistic copying are supposed to be founded upon the production of telling resemblances between an observed target and the representation. But, there was no perceptible target that Hooke's bullets could possibly resemble. Micro-level globules were wholly invisible, theoretical entities whose properties could only be known by rational inference. Worse, far from being some deft resemblance that Hooke had newly caught with his keen, microscopic eye, the rendering of quasi-atomic particles as spheroids was a central convention — even cliché — of physical thought reaching well back to classical antiquity (Lüthy 2000, Meinel 2004). Patently un-seeable, Hooke's globules could "resemble" bullets only when this convention of atomist thought was in place. And this was a matter of faith, not of observation. Therefore, if we insist upon finding a period, pictorial analogue for Hooke's crystallization model (and this is an option I exercise only rhetorically), we might look less to the still-life paintings perfected in the early modern Netherlands and instead think with contemporaneous Spanish renderings of religious visions (Stoichita 1995). Like those painters in seventeenth century Spain who drew upon a rich vocabulary of pictorial conventions to represent marvelous visions accessible to saints' eyes alone, so (this tortured reading might propose) Hooke utilized a stock atomist convention whereby elementary particles were spherical so as to visualize the imperceptible sub-structures of crystalline matter.

By clarifying this theoretical ontology of globules, Hooke's crystallization model brings us to the limits of interpretative utility for the available terms of pictorial depiction; there was simply no visible entity it could copy. Instead, this analysis indicates that a very funny thing had happened. Hooke certainly invokes the terminology resemblance or imitation to make his theoretical entities comprehensible; globules are bullet-like. But, to be "like" globules, these bullets-the key components of Hooke's crystallization model - had then to become unlike any actual, physical bullets available to familiar apprehension. How are we to understand the 
enhanced bullets that seem to populate Hooke's crystallization model? And what exactly is the nature of their "likeness" to the theorized globules?

Hooke, as we have seen, understood globules to be nearly spherical particles of matter governed by forces of congruity and incongruity that form into regular, geometrical configurations through vibrating motion. So we have also noted, physical bullets agitated on an inclining plane could not actually have generated the geometrical patterns that Hooke had claimed and depicted in Micrographia. Therefore, it is instructive to think of the bullets envisioned in this crystallization model not as actual, physical objects, but as continuous with the frictionless planes, spherical planets and other central stylizations deployed in scientific modeling. Indeed, such a view of models and their components as imagined physical entities has recently been advanced by in philosophy of science. Like literary fiction, so Roman Frigg argues, scientific models instantiate varieties of serious make-believe, fictionalizing their components to yield truths about the representational worlds they generate and enabling comparisons between those fictions and reality. Models, in this analysis, are "hypothetical entities that, as a matter of fact, do not exist spatio-temporally but ... would be physical things if they were real" (Frigg 2009, 3). Read in this way, the bullets of Hooke's model might be seen as fictionalized or imagined so that they share relevant properties with the theoretical globules. Hooke's model asks us to imagine, in other words, that if the bullets were real, they would behave like globules. And because globules are theorized to form into regular, geometrical configurations when agitated, the vibration of these fictionalized bullets would yield the geometrical patterns we see depicted in Micrographia.

Framed in this way, the relationship of "likeness" noted between Hooke's imagination-enhanced bullets and his globules can be apprehended more precisely. A useful clue in this direction is supplied by historian Penelope Gouk (1999, 218) who has described Hooke's musical, mechanical and other trials at the Royal Society as:

... attempts to prove, or at least render plausible, his theory of vibrating matter through experimental demonstration. It was on the basis of such simple and verifiable experiments that Hooke claimed analogous principles were operating beyond the range of ordinary sense perception.

If we bracket her "simplicity" and "experimental verifiability", Gouk's attention to principles of analogy is surely useful for understanding Hooke's enterprise. ${ }^{6}$ That is, the imagination-enhanced bullets are not the same as globules; but they can be

\footnotetext{
${ }^{6}$ Even if we have no specific endorsement of this line from Hooke for the crystallization model, this style of thinking certainly finds support in his contemporaneous writing. Earlier in Micrographia, Hooke had noted: "It seldom happens that any two natures have so many properties coincident or the same ... and to be different in the rest" $(1665,14)$. Therefore, he continues, "I think it neither impossible, irrational, nay nor difficult to be able to predict what is likely to happen in other particulars also ... if the circumstances that so often very much conduce to the variation of the effects be duly weigh'd and consider'd" $(1665,14)$. Appealing to classical induction, in other words, patterns observable in the bullets and numerous other vibrating phenomena the encourage inference about the properties of those imperceptible physical structures undergirding them all.
} 
seen as analogically related to them. As Mary Hesse has argued (Hesse 1966b), analogical models like this proceed by identifying properties shared between systems and eliminating their differences or negative analogies. Exploration of the better known system is then used to make predictions about the more obscure one. Therefore, we could say, Hooke's understood his enhanced bullets and his globules to share the following positive analogies: both were nearly spherical in shape; in vibrating motion; governed by forces of congruity and incongruity; and capable of forming into regular geometrical patterns. Properties they did not share might include their differences in size and frequency of vibration, or the shininess, salty taste or other accidental properties of the bullets in their possible improved state. What the model claims to offer, then, is a mechanism based on trials with the betterknown system (the enhanced bullets) through which to predict patterns generated by the obscure, theorized particles called globules at increasing levels of complexity. The data yielded by this model is what we see depicted in the figures from Micrographia.

In this light, our schematic account of the model might thus be updated in the following way:

Figures $---($ depict $)--->$ Imagined Bullets --- represent by analogy $--->$ "Globules"

Through imaginatively stylizing its putative physical company of vibrated bullets, Hooke's analogical model creates a mechanism with which to study the behavior of theorized entities. What we see represented in Micrographia are data yielded by this model.

This is intended to be a charitable reading of how Hooke's model was supposed to work. More fundamentally, it is a reading pursued as a means of rethinking both the opposition of representation versus experiment and the grip of pictorial mimesis in which Hooke's visual activities have been repeatedly plotted. Even under such limited analysis as this, however, the constraints of Hooke's model appear strikingly and tellingly acute. Rather than being too closely related to experiment as had been worried at the outset, Hooke's crystallization model ends up appearing overly distanced from it. With the bullets fictionalized into analogy with theoretical globules and no longer answering to the physical behavior of actual bullets in the trial situation Hooke had stipulated, it is hard to know how much information could possibly have been yielded by work with the model—or even what such work might have looked like. Did manipulation of actual bullets maintain any relevance to the project? Or, had the model entirely become a kind of thought experiment? ${ }^{7}$ Indeed, it is instructive to remember here how Kuhn himself observed that seventeenth century experimentalists like Hooke were actually closest in spirit to the older traditions of theory-illustrating experiment precisely in

\footnotetext{
${ }^{7}$ Further pursuit of these points could productively engage with the stimulating reading of thought experiments and fictions proposed by David Davis (see "Learning through Fictional Narratives in Art and Science" in this volume).
} 
those trials claiming to "reveal the shape, arrangement, and notion of corpuscles" $(1977,43)$.

In turning from the bullets to the arguably more successful model that Hooke devised to represent a comet with a wax ball and sulfuric acid, it is nonetheless worth stressing the representational complexity involved in the production of a seemingly humble material model like this, which Hooke himself had called a "gross Similitude". Hooke's bullets are convincingly explicable neither as the imitation of nature nor as the illustration of theory. Instead, projects like this aimed at the construction of a species of serious make-believe that could yield meaningful insight into obscure or imperceptible entities through work with a stylized representational proxy. Conventional stipulations, imaginative enhancements, analogy, and possibly deep fiction - all contributed to Hooke's seemingly innocuous study of crystals. Thus, however we wish to understand the varieties of representation instantiated by its images, the crucial point is that the pictures found in Micrographia are data from Hooke's modeling enterprise, not the privileged interpretive key to it. If anything, pictures were but one facet of the experimentalist's representational approach as it moved between theory, performance and material practice.

\section{In Some Things Analogous to the One, and Somewhat to the Other, Though not Exactly the Same with Either}

In the last weeks of April 1677, a comet became perceptible in the skies above northern Europe. From his observation turret in London's Gresham College, Robert Hooke studied the comet from April 21 until it disappeared a week later. (see Hooke 1935, 286-287) Even without the assistance of the six and fifteen foot reflecting telescopes that Hooke used in his private observatory, the comet's teardrop tip and broom-like tail must have cut an impressive figure above the nocturnal cityscape of later seventeenth century London (Fig. 2). So the illustrative plate prepared by engraver Francis Lamb from Hooke's own drawings suggests, the Curator was fascinated by comets and committed significant energy to their study. But while he cast a jaundiced eye upon the millenarian prognostications that they elicited amongst the early modern European public, Hooke also had doubts about the calculations of comets' orbits and parallax motions as produced by his scientific contemporaries. Instead, Hooke took a typically pragmatic course in his own studies. Recognizing the limits of available instruments to provide accurate information about comets' speed, distance from the Earth, and possible orbits, he concentrated on what could be learned about comets from observation. Based upon his studies of the 1677 object, Cometa of 1678 set out an impressive account of how comets come to exhibit their characteristic features: an antisolar tail, luminosity and erratic motion. Briefly elucidating the theory he set out in 1678, I want to turn to the sequence of models Hooke contrived to reconcile this theory with his observations.

In Cometa, Hooke postulates that a comet begins as a semi-solid, spheroid body and gradually decomposes due to its significant internal instabilities. Utilizing the 
style of reasoning we have seen him deploying in his earlier crystallization model, Hooke found evidence for comets' instability through analogy with the behavior of the Earth. Although it seems to be "generally very dense, compact, and very closely and solidly united", Hooke's pioneering lectures on the Earth's volcanic eruptions and magnetic variations had shown that the planet "may be notwithstanding more loose, and ununited, and moveable from certain causes" (1678b, 11, Drake 1996). Comets, he proposes, are similar, albeit in a more extreme form: "It seems very probable to me, that the body of Comets may be of the same nature and constitution with that of the internal parts of the Earth, that these parts may by the help of the Aether, be so agitated and blended together, as to make them work upon, and dissolve each other" (1678b, 11-12). Susceptible to the reagent aether because of this internal agitation, the comet's disintegration accelerates, causing it to lose mass and gravitational force. And because he understood gravitation through the aforementioned dynamics of congruity and incongruity, Hooke was provided with an explanation of the formation of the comet's tail:

The parts thus dissolved are elevated to a greater distance from the center of the Star or Nucleus, or the superficies of it, whose gravitating or attractive principle is much destroyed, ... but having given those parts leave thus far to ramble, the gravitating principle of another body more potent acts upon it, and makes those parts seem to recede from the center thereof, though really they are but as it were, left behind the body of the Star, which is more powerfully attracted that the minuter streaming parts $(1678 \mathrm{~b}, 12)$.

As the head of the comet inclines towards the gravitating body of the sun with which it is congruous, so the more incongruous particles of the tail trail behind. In this way, Hooke's theory of internal agitation compounded by reaction to aether could explain the comet's characteristic, observable trait of the anti-solar tail, which had been depicted so elegantly in Cometa's plates.

Hooke's theory could also offer an account of comets' peculiar celestial motion. Once destabilized, he argues, the comet's magnetic relations become disturbed, no longer holding it in "that circular way" of a stable orbit (1678b, 13). Instead, the comet "flies away from its former center by the Tangent line to the last place, where it was before this confusion was caused in the body of it" (1678b, 13). Projecting tangentially outward from its former orbital trajectory, the comet enters into the gravitational fields of other bodies in its new path. Such attractions only intensify its disintegration, thereby lengthening its tail to upwards of seventy telescopic degrees $(1678 \mathrm{~b}, 13)$. Combined with the reaction to aether and compounded by the attraction of neighboring celestial bodies, comets' internal agitation informs Hooke's account of their enigmatic orbital behavior. ${ }^{8}$ What Cometa effectively offers, then, is a theoretical template for explaining the observed form and unusual trajectories of comets, while elucidating their genesis from the deterioration of stable celestial bodies.

In turning from this theory to the material models Hooke would use to reconcile it with observation, I want to draw more explicitly upon studies of modeling from

\footnotetext{
${ }^{8}$ For Hooke's broader understanding of the internal motion of planetary bodies, see Hooke's Lectures and Discourse of Earthquakes in Hooke (1705, 149-190).
} 
recent analytic philosophy of science, which remain largely unknown in art history and visual studies. Since the early 1960s, the study of models has occupied center stage in the philosophy of science, and both their relation to theory and to their respective targets have been the subject of heated debate. One crucial argument of this literature has been that models do not simply illustrate or instantiate abstract theories. Instead, they frequently depart in important ways both from the theories they ostensibly embody and the worldly targets they are used to explore. This view has received its most advanced statement within the so-called Models as Mediators project (Morgan and Morrison 1999). Multifarious in form and often intractable in function, models might thus be said to possess "lives of their own". Because of their partial independence or "autonomy", this literature argues that we see models as standing between - thus, mediating - theory and experimental engagement with nature. Although it is not above critique ${ }^{9}$, this "models-as-mediators" approach is particularly useful for elucidating how Robert Hooke worked with his material representations of comets in the late 1670s.

Once he had set out his theory of their physical form, Hooke offered the reader of Cometa a way to "make a perfect representation of the body, and beard [i.e. tail] of the Comet" (1678b, 31). As he directs:

Take a very clear long Cylindrical Glass, which may hold about a quart of water; fill it three quarters full with water, and put into it a quarter of a pound of Oyl of Vitriol [sulfuric acid], and in the midst of this suspend by a small silver wire, a small wax-ball, rould in filings of iron or steel, and you may plainly observe a perfect representation of the Head, Halo, and Beard of the Comet (1678b, 31).

Although I have not been able to replicate this action even to the modest degree of Hooke's crystallization model, the chemistry it requires is relatively simple. The iron in the filings covering the head of the "comet" reacts with the sulfuric acid to create hydrogen gas. These hydrogen bubbles rapidly rise to the surface of the acid solution, which has been diluted with water presumably to control the rate of reaction. ${ }^{10}$ In a general sense, Hooke's account might be read to suggest that the reaction of the acid and the ferrous particles in the wax ball yields a visual effect resembling his target system; the bubbling ball looked like a comet. Yet, Hooke's model repays consideration in different sense-one wherein observation and manipulation of this strange, effervescent cocktail leads to knowing about extraterrestrial bodies. For, this model departed in important ways not only from Hooke's observations of meteoric bodies in April 1677, but from his theory of comets more broadly. How and exactly what this mediating model represented thus needs to be examined carefully.

To elaborate these points, I want to make use of the "DDI" (denotation, demonstration, and interpretation) analysis put forward by philosopher of science R.I.G.

\footnotetext{
${ }^{9}$ For a critique, see Giere (1999).

${ }^{10}$ I thank David Tirrell and Tony Jia for discussing this action with me.
} 
Hughes (1997). Although but one of several approaches to the study of models available within recent philosophy of science, Hughes' account is particularly useful here insofar as it specifically avoids appeal to mimesis. Instead, integrating Nelson Goodman's claim that resemblance is neither a necessary nor sufficient condition for representation, Hughes' analysis can help us to peel back the veneer of plausibility that attends to Hooke's model and to schematize its structure. First, following Hughes' approach, we need to isolate what the model denotes. The wax ball in the model denotes the solid core of the comet, which Hooke had theorized "to be made of solid matter, not fluid; that the body of it especially, is considerably dense, but that the haziness or Coma about it is much more rarified, and the tail thereof is most of all" $(1678 \mathrm{~b}, 9)$. Secondly, the dramatic reaction of the comet to surrounding aether is denoted in the model by the evolution of hydrogen gas from the iron and sulfuric acid. As with comets, Hooke observed, "the menstruum falling on, or dissolving the iron, there is a continual eruption of small bubbles, and dissolv'd particles from the sides of this body" (1678b, 31-32). Finally, the force of solar gravitation that produces the comet's characteristic tail is denoted in the model by the gravitation of the earth upon the glass tube and its contents. "Being of a much lighter consistence than the anbient liquor", Hooke explains, bubbles in the glass tube denote the particles that "are by the greater gravity of that, continually protruded upwards" to simulate the tail of the comet $(1678 b, 32)$.

In the second stage of schematic analysis that Hughes calls "demonstration", we set out how the representational terms of the model can lead to new understanding of the target. Hooke explains this dynamic in the following way: "If we suppose the Aether to be somewhat analogous to a menstruum, and that there is a gravitation towards the center of the Sun, if the Nucleus or head of the Comet be supposed such a dissoluble substance, the phaenomena of the shape of the Comet may, I think, be rationally explained" $(1678 b, 32)$. Having appointed denotational values to humble materials and forces, Hooke's model provides a scenario in which the consequent effects may be observed. Visualizing the comet as a field of ferrous particles reacting with sulfuric acid, the material model creates an opportunity to observe the simulated forces of gravitation and aether-resistance upon elusive meteoric bodies, which could never be examined "first hand".

What makes this model especially interesting are the ways in which Hooke sought to gain cognitive purchase on comets through reconciling study of this materialization with observational data. Although our only surviving evidence of Hooke's actual work with his model comes from the following remarks, he makes clear that observation and manipulation of the bubbling wax ball could enable the scientist to "interpret" (in Hughes' terminology) the relations between model and target phenomena. So Hooke claims:

\footnotetext{
By this Hypothesis [i.e. the model] the phaenomena of the Comet may be solved; for hence 'tis easie to deduce the reason why the Beard grows broader and broader, and fainter and fainter towards the top: why there is a Halo about the body; for this will appear clearly in the experiment: why the Beard becomes a little deflected from the body of the Sun; for if the dissolving Ball be by the wire mov'd either this way or that way, the arising steam or
} 
bubbles will bend the contrary: ... by this supposition also 'twill be easie to explicate why the beard is sometime bended, and not straight, and why it is sometimes brighter upon the one side than upon another? why the bottom of it is more round, and the other sides more undefin'd; and divers of the like phaenomena $(1678 \mathrm{~b}, 32)$.

By Hooke's analysis, observation and intervention into the behavior of the material model-including moving the wax ball "this way or that"-calls attention to phenomena observable in comets themselves. The bent stream of bubbles caused by manipulation of the model allows the investigator to hypothesize the presence of similar effects in the target system and to draw inferences about their causes. In this way, the model possesses what Hughes calls an "internal dynamic" that enables the user to draw "hypothetical conclusions about the world over and above the data we started with" (1997, S331).

How exactly did this chemical cocktail thereby represent Hooke's comet? Ingenious as this material model was, it stood in uncomfortable relation both to crucial aspects of Hooke's theory of comets and to what he had actually observed in April 1677. As we have seen, Hooke made much of the ability of his bubbling wax ball to model the reaction between aether and the meteoric body that created the comet's tail. Yet, by privileging factors that could be admirably visualized in the model such as dissolution in a reagent and its response to the force of gravity, Hooke had to compromise a crucial piece of his comet theory. After all, he had claimed that what made comets exhibit behavior so notably different from other satellites similarly exposed to the corrosive effects of aether was their extreme internal agitation. ${ }^{11}$ In concert with the action of the aether, it was this internal activity that Hooke theorized as causing the destabilization of the proto-comet's gravitational and magnetic properties, while completely altering its orbital trajectory. In his material model, however, the decomposition of the comet was simulated as an exclusively and literally superficial process. The reader had been told how the solid wax core should be "rould in filings of iron or steel" $(1678 \mathrm{~b}, 31)$. It would be fascinating to know if and how Hooke might have attempted to engineer a model closer to his theory that could simultaneously deteriorate from discrete, yet complementary, internal and external causes. Nonetheless, the evidence we have suggests that the materiality of Hooke's made-model not only simplified but significantly departed from this crucial component of his comet theory.

More problematic for Hooke was the fact that the wax ball also failed to match a key feature of observed comets: the model could not generate light. ${ }^{12}$ Here too the philosophical literature on mediating models is instructive. What this literature has emphasized is that because models can represent their targets only partially, scientists frequently compensate by generating numerous different models of any given system under examination. The various different models of the nucleus used in physics are exemplary. As Margaret Morrison and Mary S. Morgan observe: "Each

\footnotetext{
${ }^{11}$ Hooke did not know that the earth too possesses an antisolar ion tail; see Yeomans (1990, 352).

${ }^{12}$ In 1682, Hooke described a revised version of this material model that could produce light; see Hooke $(1705,167)$.
} 
individual model fails to incorporate significant features of the nucleus, for example, the liquid drop [model] ignores quantum statistics and treats the nucleus classically. While others ignore different quantum mechanical properties, they nevertheless are able to map onto technologies in a way that makes them successful, independent sources of knowledge" (1999, 23-24). Hooke's response to the limits of his wax-ball comet model is telling in this way. Conceding its inability to explain the important, observed feature of luminescence, Hooke concludes Cometa by canvassing a wide field of other possible models for comets' generation of light. "Decaying fish, rotten wood, glow-worms, \&c." are all offered as possible analogues before Hooke introduces a new set of models $(1678 \mathrm{~b}, 46)$. A comet's luminous head, he postulates, is like a torch or a battery of cannons whose "blazing Granadoes or Fire-balls" follow the parabolic motion of projectiles as established by seventeenth century physicsand so we see visualized in a compelling diagram also provided in Cometa $(1678 \mathrm{~b}$, 46, 48) (Fig. 2).

Although these postulations are given little further treatment, Hooke's tactical or pragmatic approach to representation becomes increasingly clear over the course of Cometa. None of his various comet models can promise to fully reconcile theory and observation. But each can denote discrete, appointed features and thereby offer to bring aspects of cometary phenomena into demonstration and interpretation. Stating a veritable motto of this approach to representation, Hooke concludes of his models that comets are "in some things analogous to the one, and somewhat to the other, though not exactly the same with either" $(1678 b, 47)$. By way of conclusion, I want to suggest how historians of art might productively learn from this representational pragmatism, particularly as we study visual practices generated at the boundaries of early modern art and science. Beyond the important insight it offers to the historical context of Robert Hooke and his colleagues, though, this analysis also allows us to reconsider the integral problems shared by students of the visual and philosophers of science on a larger scale.

\section{It Behove Them, Who Professe the Knowledge of Nature or Reason, Rightly to Apprehend the Severall Waies Whereby They may be Expressed}

Trained as a painter and gifted as an experimenter, English philosopher Robert Hooke has risen to prominence in recent historical studies that have celebrated the connections between visual art and the "new sciences" of seventeenth century Europe. The lavish plates of Hooke's Micrographia have been repeatedly cited as evidence of this union. Made from observations with optical instruments, they suggest both the keen-eyed attentiveness to optical detail seen in seventeenth century painting and the guiding imprint of a novel conception of experiment- the production of new facts about nature through what Francis Bacon called the "vexations of art". By contrast, as has been the case more broadly (Hopwood and de Chadarevian 
2004), Hooke's material models have received markedly less attention. ${ }^{13}$ Reasons for this neglect are perhaps not difficult to find. Unlike the stunning illustrative plates of Micrographia, Cometa or Hooke's numerous other publications, no direct physical evidence is known to survive from his material models. In this way, they challenge both the time-honored methods of art-historical analysis and the favor for material culture exhibited in recent history of science (Galison 1997, Daston 2004). To make matters worse, no physical evidence may ever have existed of these models. As we have seen, it is difficult to know if and how Hooke's crystallization model - a representation wherein bullets with imagined properties were used to generate behavior of theoretical entities - ever actually required physical objects. Treading such uncomfortable ground between categories of experiment and theory, Hooke's models were strange, intermediary enterprises that could answer exactly to neither category and that departed in important ways from both.

With these doubts in mind, we might return to the quasi-existential question sketched at the outset. Why exactly should art historians or other students of the visual bother with these baffling activities which only seem to complicate the attractive, available view of Hooke and his colleagues as able copyists of natural facts? As is implicit in the foregoing argument, what I see as at stake in engaging with the evidence of material models are matters essential to the historical understanding of early scientific visuality and to the conceptual vitality of the art/science conversation. I will treat the historical argument first. We know that early scientific bodies like the Royal Society of London were organized around and gave particular privilege to experimental trials. However, as is revealed in the work of Robert Hooke, the Royal Society's central experimental performer and theorist, trials that initially appear to be clear-cut cases of experimentation may actually be better understood as varieties of representation. If glimpsed only fragmentarily through the modest sampling presented here, these models were various in form and diverse in function; they deployed varieties of representational strategy and were allotted different degrees of cognitive value. Now, such interest in employing a broad range of representations and commanding an expanded field of visual activity are importantly commensurate with the evidence of recent historical studies, which are altering our apprehension of visuality in the early Royal Society. If recent studies have shown how Hooke and Wren were polymathic masters of drawing, architecture, surveying and numerous other visual practices, their scientific colleagues in the Royal Society's ambit were no less inclined to experimenting with representation; they contrived ingenious of modes of encryption, pictographic writing, and automated notation along with forays into optical projection and anamorphic wizardry. ${ }^{14}$

The crucial, historical point to be apprehend here is that those in the early scientific community identified such polymorphous visual fluency as a virtue. Not long before he served as a mentor to Robert Hooke at Oxford, catalyst of seventeenth century English science John Wilkins published a text on cryptography. Therein,

\footnotetext{
${ }^{13}$ A rare exception here is Iliffe (1995, esp. 293-299).

${ }^{14}$ For extended discussion, images and further bibliography, see Hunter (2007).
} 
Wilkins claimed: "As it will concerne a man that deals in trafficke, to understand the severall kinds of money, and that it may be framed of other materialls besides silver and gold, so likewise do's it behove them, who professe the knowledge of nature or reason, rightly to apprehend the severall waies whereby they may be expressed" $(1641,11)$. If Wilkins' dictum is keenly pertinent for understanding Hooke's approach to modeling as exposited here, it is more broadly instructive for what has emerged as an important direction in recent studies of early modern art and science. As we have seen with Hooke's models of the comet, being able to harness a range of representations culled from the imaginative interpretation of physical processes was critically advantageous to the experimental philosopher. But, this broad-ranging knowledge of physical materials and their imaginative, representational potential was simultaneously crucial to the architectural and other visual activities that Hooke, Wren and others practiced in later Baroque London. Thus, drawing tools from philosophy of science, we may better analyze the diverse representational techniques actually deployed and valued by early experimental philosophers. More fundamentally, we can simultaneously apprehend how diverse forms and functions of visual practice were essential to the science and art engineered by figures like Hooke and Wren. Rather than just reinforcing the familiar linkage of naturalism in painting and empiricism in science, this interpretation would advance by analyzing the performances and procedures at the very center of their scientific community's attention.

This leads to the second, conceptual point. For, what recent work in philosophy asks us to recognize in scientific representations are degrees of complexity, sophistication and, above all, degrees of distance from natural targets that are almost entirely absent from humanities-based accounts. In his contribution to this volume, for example, Anjan Chakravartty treats the contention that "descriptions of entities and processes afforded by scientific representations are generally false, strictly speaking", as so uncontroversial a claim that it necessitates no further argument. Cutting directly against the grain of much received wisdom in humanities-based art/science studies, such philosophical work ask us to see scientific models as stylized artifacts invested with cognitive value and modified by varieties of imaginative intervention. Introduced into serious games of make-believe, these models can mediate between observables and theory, generating meaningful insight into real-world systems even as they are highly indifferent to particular facts about their targets. To art historians and humanists more generally, questions of how ostensibly fictional objects can be invested with imaginative values and take on "lives of their own" are not marginal matters. As only the seminal volumes of David Freedberg (1989), Hans Belting (1994) and W.J.T. Mitchell (2005) need indicate, such questions are absolutely central to the Western artistic tradition.

In thinking with this research in philosophy of science, then, historians of art might reconsider both the conception of scientific representation now dominant in the humanities and the archive from which that conception has been drawn. As noted at the outset, pictures and illustrations have long served humanists as the crucial evidence of representation in science. These pictures have also come to be seen not only as the key archive of scientific representation but also the acme of its aspirations. So 
Robert Hooke's work examined here suggests, though, pictorial artifacts constitute only a fragmentary component of the highly imaginative, stylized ways in which natural objects may be manipulated, fictionalized and performed as representations to advance scientific understanding. Examining exactly what these "clever objects" are and how they embody, direct or inform imaginative thought are questions we might begin to ask. But, these are questions we can also share. For if we can learn from the methods and ethos of recent philosophy of science, so art historians can bring to discussion the discipline's rich tradition of thinking about the properties of the aesthetic object and the various powers over the imagination latent to it. Our conversation need not be to explain "Art" by virtue of "Science" (or vice versa), but to theorize the representational practices that run between them and beyond them.

Acknowledgments Thanks to Moti Feingold, Tarja Knuuttila and, especially, to Roman Frigg for comments on previous drafts of this essay.

\section{References}

Alpers, S. (1983), The Art of Describing: Dutch Art in the Seventeenth Century. Chicago: University of Chicago Press.

Aristotle (1987), The Poetics of Aristotle, trans. S. Halliwell. London: Duckworth.

Baird, D. (2004), Thing Knowledge: A Philosophy of Scientific Instruments. London: University of California Press.

Bellori, G. P. (2005), The Lives of the Modern Painters, Sculptors and Architects, trans. A.S. Wohl. Cambridge: Cambridge University Press.

Belting, H. (1994), Likeness and Presence: A History of the Image before the Era of Art, trans. E. Jephcott. Chicago: University of Chicago Press.

Bennett, J., et al. (2003), London's Leonardo: The Life and Work of Robert Hooke. Oxford: Oxford University Press.

Bermingham, A. (2000), Learning to Draw: Studies in the Cultural History of a Polite and Useful Art. New Haven: Yale University Press.

Braider, C. (2004), Baroque Self-Invention and Historical Truth: Hercules at the Crossroads. Aldershot: Ashgate.

Bredekamp, H. (2000), "Gazing Hands and Blind Spots: Galileo as Draftsman”, Science in Context 13, 3-4: 423-462.

Chapman, A. (1996), "England's Leonardo: Robert Hooke (1635-1703) and the Art of Experiment in Restoration London", Proceedings of the Royal Institution of Great Britain 67: 239-275.

Cole, W. (ca. 1692), MS 1078. Wellcome Library, London.

Cooper, M. (2003), 'A More Beautiful City': Robert Hooke and the Rebuilding of London after the Great Fire. Sutton: Thrupp-Stroud.

Crombie, A. C. (1994), Styles of Scientific Thinking in the European Tradition. vol. II. London: Duckworth.

Daston, L. (ed.) (2004), Things That Talk: Object Lessons from Art and Science. New York: Zone.

Daston, L. and Galison, P. (2007), Objectivity. New York: Zone.

Drake, E. T. (1996), Restless Genius: Robert Hooke and his Earthly Thoughts. New York: Oxford University Press.

Edgerton, S. Y. Jr. (1984), “Galileo, Florentine 'Disegno,' and the 'Strange Spottednesse' of the Moon'”, Art Journal 44, 3: 225-232.

Ehrlich, M. E. (1992), "Mechanism and Activity in the Scientific Revolution: The Case of Robert Hooke", Annals of Science 52: 127-151. 
Elkins, J. (1999), The Domain of Images. Ithaca: Cornell University Press.

Elkins, J. (2007), Visual Practices Across the University. Munich: Wilhelm Fink Verlag.

Elkins, J. (2008), Six Stories from the End of Representation: Images in Painting, Photography, Astronomy, Microscopy, Particle Physics, and Quantum Mechanics, 1980-2000. Stanford: Stanford University Press.

Freedberg, D. (1989), The Power of Images: Studies in the History and Theory of Response. Chicago: University of Chicago Press.

Freedberg, D. (2002), The Eye of the Lynx: Galileo, His Friends and the Beginnings of Modern Natural History. Chicago: University of Chicago Press.

Frigg, R. (2006), "Scientific Representation and the Semantic View of Theories", Theoria 55: $49-65$.

Frigg, R. (2009), "Models and Fictions", Synthese; preprint available at http://www.lse. ac.uk/collections/CPNSS/projects/ContingencyDissentInScience/DP/DPFriggOnline0508.pdf

Frigg, R. and Hartmann, S. (2006), "Models in Science", in E. N. Zalta (ed.), Stanford Encyclopedia of Philosophy, http://plato.stanford.edu/archives/spr2006/entries/modelsscience/

Fyfe, G. and Law, J. (eds.) (1988), Picturing Power: Visual Depiction and Social Relations. London: Routledge.

Gal, O. (2002), Meanest Foundations and Nobler Superstructures: Hooke, Newton, and the "Compounding of the Celestiall Motions of the Planetts". London: Kluwer.

Galilei, G. (1974), Two New Sciences, trans. S. Drake. Madison: University of Wisconsin Press.

Galison, P. (1997), Image and Logic: A Material Culture of Microphysics. Chicago: University of Chicago Press.

Gibson-Wood, C. (2000), Jonathan Richardson: Art Theorist of the English Enlightenment. New Haven: Yale University Press.

Gibson-Wood, C. (2002), "Picture Consumption in London at the End of the Seventeenth Century", Art Bulletin 84, 3: 491-500.

Giere, R. (1999), "Using Models to Represent Reality", in L. Magnani et al. (eds.), Model-Based Reasoning in Scientific Discovery, London: Kluwer, 41-57.

Golinski, J. (1989), "A Noble Spectacle: Phosphorous and the Public Cultures of Science in the Early Royal Society", Isis 80, 1: 11-39.

Gombrich, E. (1961), Art and Illusion: A Study in the Psychology of Pictorial Representation. London: Phaidon.

Goodman, N. (1968), Languages of Art: An Approach to a Theory of Symbols. New York: BobbsMerrill.

Gouk, P. (1999), Music, Science and Natural Magic in Seventeenth-Century England. New Haven: Yale University Press.

Hacking, I. (1983), Representing and Intervening: Introductory Topics in the Philosophy of Natural Science. Cambridge: Cambridge University Press.

Halliwell, S. (2002), The Aesthetics of Mimesis: Ancient Texts and Modern Problems. Oxford: Princeton University Press.

Henry, J. (1989), "Robert Hooke, the Incongruous Mechanist", in M. Hunter and S. Schaffer (eds.), Robert Hooke: New Studies, Woodbridge: Boydell, 149-180.

Hesse, M. (1966a), "Hooke's Vibration Theory and the Isochrony of Springs", Isis 57, 4: 433-441.

Hesse, M. (1966b), Models and Analogies in Science. Notre Dame: University of Notre Dame Press.

Hockney, D. (2001), Secret Knowledge: Rediscovering the Lost Techniques of the Old Masters. New York : Viking Studio.

Hooke, R. (1665), Micrographia: or, Some Physiological Descriptions of Minute Bodies made by Magnifying Glass. London: John Martyn and James Allestry.

Hooke, R. (1678a), Lectures de Potentia Restitutiva, or of Spring Explaining the Powers of Springing Bodies. To which are Added some Collections. London: J. Martyn. 
Hooke, R. (1678b), Lectures and Collections. London: J. Martyn.

Hooke, R. (ca 1680), MS Sloane 1039. London: British Library.

Hooke, R. (1705), The Posthumous Works of Dr. Robert Hooke, in R. Waller (ed.), London: S. Smith and B. Walford.

Hooke, R. (1726), Philosophical Experiments and Observations of the Late Eminent Dr. Robert Hooke, in W. Derham (ed.), London: W. \& J. Innys.

Hooke, R. (1935), The Diary of Robert Hooke, 1672-1680, in H.W. Robinson and W. Adams (eds.), London: Taylor \& Francis.

Hughes, R. I. G. (1997), "Models and Representation", Philosophy of Science, Vol. 64, Supplement. Proceedings of the 1996 Biennial Meetings of the Philosophy of Science Association. Part II: Symposia Papers: S325-S336.

Hunter, M. (2007), Robert Hooke Fecit: Making and Knowing in Restoration London. PhD Dissertation: University of Chicago.

Hunter, M. (2010), "The Theory of the Impression According to Robert Hooke", in M. Hunter (ed.), Printed Images in Early Modern Britain: Essays in Interpretation, Aldershot: Ashgate, 164-193.

Hunter, M. (1981), Science and Society in Restoration England. London: Cambridge University Press.

Hunter, M. (2003), "Hooke the Natural Philosopher", in J. Bennett et al. (eds.), London's Leonardo: The Life and Work of Robert Hooke, Oxford: Oxford University Press, 105-162.

Iliffe, R. (1995), "Material Doubts: Hooke, Artisan Culture and the Exchange of Information in 1670s London", British Journal for the History of Science 28 (March 1995): 285-318.

Ivins, W. M. Jr. (1938), On the Rationalization of Sight; with an Examination of Three Renaissance Texts on Perspective. New York: Metropolitan Museum of Art.

Jardine, L. (2003a), The Curious Life of Robert Hooke: The Man Who Measured London. London: Harper Perennial.

Jardine, L. (2003b), On a Grander Scale: The Outstanding Career of Sir Christopher Wren. London: HarperCollins, 2003.

Jongh, E. de (1984), "The Art of Describing: Dutch Art in the Seventeenth Century", Simiolus XIV/1: 51-59.

Kemp, M. (1990), The Science of Art: Optical Themes in Western Art from Brunelleschi to Seurat. New Haven: Yale University Press.

Koerner, J. (1999), "Factura", Res 39 (Autumn): 5-19.

Kuhn, T. (1977), The Essential Tension: Selected Studies in Scientific Tradition and Change. Chicago: University of Chicago Press.

Lee, R. (1940), "Ut Pictura Poesis: The Humanistic Theory of Painting", Art Bulletin 23: 197-269.

Lindberg, D. (1976), Theories of Vision from Al-Kindi to Kepler. Chicago: University of Chicago Press.

Lüthy, C. (2000), "The Invention of Atomist Iconography", Max-Planck-Institut für Wissenschaftsgeschichte, Preprint 141. Berlin.

Lynch, M. and Woolgar, S. (eds.) (1990), Representation in Scientific Practice, London: MIT Press.

Marin, L. (1986), "In Praise of Appearance", October 37: 98-112.

Marin, L. (1995), To Destroy Painting, trans. M. Hjort. Chicago: University of Chicago Press.

Meinel, C. (2004), "Molecules and Croquet Balls", in S. de Chadarevian and N. Hopwood (eds.), Models: The Third Dimension of Science, Stanford: Stanford University Press, 242-275.

Mitchell, W. J. T. (2005), What Do Pictures Want? The Lives and Loves of Images. Chicago: University of Chicago Press, 2005.

Morgan, M. S. and Morrison, M. (eds.) (1999), Models as Mediators: Perspectives in Natural and Social Science. Cambridge: Cambridge University Press.

Muller, J., et al. (eds.) (1984), Children of Mercury: The Education of Artists in the Sixteenth and Seventeenth Century. Providence: Brown University Press.

Newton, I. (1989), Mathematical Principles of Natural Philosophy, trans. A. Motte. Chicago: University of Chicago Press. 
Ogilvie, B. (2006), The Science of Describing: Natural History in Renaissance Europe. London: University of Chicago Press.

Pächt, O. (1950), "Early Italian Nature Studies and the Early Calendar Landscape", Journal of the Warburg and Courtauld Institutes XIII, 1-2: 13-47.

Panofsky, E. (1962), "Artist, Scientist, Genius: Notes on the 'Renaissance-Dämmerung"”, in W. K. Ferguson et al. (eds.), The Renaissance: Six Essays, New York: Harper \& Row, 121-182.

Panofsky, E. (1968), Idea: A Concept in Art Theory, trans. J.S. Peake. New York: Harper \& Row.

Pears, I. (1988), The Discovery of Painting: The Growth of Interest in the Arts in England 1680-1768. New Haven: Yale University Press.

Shapin, S. (1999), "The House of Experiment in Seventeenth-Century England", in M. Biagioli (ed.), The Science Studies Reader, New York: Routledge, 479-504.

Shapin, S. and Schaffer, S. (1985), Leviathan and the Air Pump: Hobbes, Boyle and the Experimental Life. Princeton: Princeton University Press.

Smith, P. H. (2004), The Body of the Artisan: Art and Experience in the Scientific Revolution. Chicago: University of Chicago Press.

Stafford, B. M. (1991), Body Criticism: Imaging the Unseen in Enlightenment Art and Medicine. London: MIT Press.

Steadman, P. (2002), Vermeer's Camera: Uncovering the Truth behind the Masterpieces. New York: Oxford University Press.

Stevenson, C. (2005), "Robert Hooke: Monuments and Memory", Art History 28, 1: 43-73.

Stoichita, V. (1995), Visionary Experience in the Golden Age of Spanish Art, trans. A.-M. Glasheen. London: Reaktion.

Waterhouse, E. (1953), Painting in Britain, 1530-1790. New Haven: Yale University Press.

Wilkins, J. (1641), Mercury; Or, The Secret and Swift Messenger. London: I. Norton.

Wilson, S. (2002), Information Arts: Intersections of Art, Science and Technology. Cambridge: MIT Press.

Yeomans, D. K. (1990), Comets: A Chronological History of Observation, Science, Myth and Folklore. Chichester: Wiley Science Editions. 